\title{
Weapon-carrying and the reduction of violent harm
}

lain R Brennan

\section{Introduction}

\section{Violence, weapon use and public health}

Weapon use in a violent incident is strongly associated with injury severity (Zimring 1968; Brennan et al 2006; Cook 2018) and removing weapons from violent encounters would significantly reduce the global burden of violent harm. Recognition of the harm potential of weapons, alongside the positioning of violence as a public health issue (Dahlberg and Mercy 2009; World Health Organization 2002), has led to weapon-carrying becoming a shared priority for criminal justice and public health policy-makers and researchers (WHO 2002; Williams and Donnelly 2014).

Although not usually discussed in these terms, the prevention of weaponcarrying should be seen as a form of 'harm reduction'. Emerging from public health research in the $1980 \mathrm{~s}$, harm reduction is a philosophical and practical approach that prioritises reducing the harm of risky behaviours over their prevention or prohibition. With the exception of research in the areas of drugs and sex work, and despite its emphasis on crime prevention, criminology has not embraced this agenda. However, three factors suggest that criminology is ready to engage with a harm reduction approach to violence. Firstly, the development (Sherman et al 2016) and adoption of measures of criminal harm (Statistics Canada 2009) indicates an intellectual and practical turn towards locating crimes - particularly violence - along a spectrum of harm rather than as discrete 
events. Secondly, the expansion of the 'law enforcement and public health' movement (van Dijk and Crofts 2016) represents a convergence of public health and criminological approaches to violence prevention. Thirdly, while violent crime is at historically low levels, the proportion of violence involving weapons has remained constant, suggesting that weapon use is a sensible next target for violence reduction activity. In an effort to build further momentum, this paper suggests that the harm reduction agenda should seek to incorporate violence prevention, specifically by removing weapons from violent encounters. It demonstrates that criminology and public health have much to offer each other in the way that they theorise about violence and apply knowledge for prevention. In demonstrating the potential links between the fields, this paper identifies risk factors for carrying a weapon by young people in England and Wales and advances theories of weapon-carrying by showing the predictive value of a socialecological frame for modelling weapon-carrying and identifying a criminological factor in the decision to carry a weapon that has been overlooked by public health researchers - trust in the police.

\section{Weapons and violence in England and Wales}

With fewer than 10 murders per million people (Office for National Statistics 2016), England and Wales is one of the world's safest places (United Nations Office on Drugs and Crime 2013). Illegal firearm ownership and firearm-related murder is rare and knives are the most commonly-used weapons (Office for National Statistics 2016). Despite the low rate of murder, a $22 \%$ increase in youth homicide between March 2016 and March 2017 has led to claims that 
England and Wales - particularly London - is experiencing an 'epidemic of knife crime' (Jones 2017). This increase in fatalities has focused the attention of the media and politicians on the prevention of 'knife crime' and has prompted strategic responses by government (Mayor of London 2017; HM Government 2018) and police (Metropolitan Police 2018). This increased focus on 'knife crime' in England and Wales and, by extension, weapon-carrying, has exposed the fact that risk factors for weapon-carrying in England and Wales have not been rigorously modelled using a national sample.

\section{The burden of violence and weapon-carrying}

The use of weapons increases the burden of violence in two ways: direct harm and contagion. Firstly, violence with a weapon tends to result in more serious injury than violence without a weapon (Brennan et al 2006; Cook 1979). In England Wales, knives were used in only $7 \%$ of all violence in $2015 / 16$, but $37 \%$ of murders (Office for National Statistics 2017). Secondly, at a community level, weapon lethality is proportional to demand. The introduction of a new weapon type to community violence signals an increase in the overall riskiness of the area, which increases demand for more lethal weapons among those who do not have them. This contagion phenomenon has been observed in social groups (Djikstra et al 2010; Tracy, Braga, and Papachristos 2016), neighbourhoods (Wilkinson and Fagan 1996) and large cities (Blumstein and Cork 1996) and, as much as the acute effects on violent harm, demonstrates why any violence prevention or harm reduction strategy must address weapon use. 
Despite the disproportionate harm that weapons can cause, explanations of weapon-carrying or weapon use have, in general, been limited to viewing it either as an extension of violence in general - thus, reducing the need for a distinct theory of weapon-carrying - or suggesting, simplistically, that it is a direct response to fear of victimisation (Button and Worthen 2017; Lemos 2004). Perhaps more promisingly, Djikstra et al (2010) have proposed that weaponcarrying is the result of interaction between individual trait aggression and aggressive peer influence, while Brennan (2017) has suggested that weaponcarrying is an attempt to reduce the uncertainty of violent encounters in risky environments. Bottom-up, risk factor-driven efforts to explain weapon-carrying have yielded further insight into this behaviour by identifying who carries weapons rather than focusing on why. These studies, usually undertaken by public health researchers, have been broad in scope, but narrow in how they have hypothesised mechanisms of weapon-carrying. The present study goes beyond the limitations of these studies - summarised below - by retaining their breadth of scope and introducing a criminological risk factor, trust in the police, that advances the understanding of why young people carry weapons.

\section{Theories of weapon-carrying: A social-ecological perspective}

Despite being a discipline that is, in general, theoretically rich, a limitation of criminological research is the tendency towards explaining violence through a single mechanism (Sampson and Lauritsen 1994). Biological, learning, differential association, ecological and structural theories of violence all have empirical support, but none alone provide a comprehensive explanation of violent 
behaviour. While integrated criminological theories of violence have existed since the 1960s (Messner et al, 1989), they remain obscure when compared to the popularity of single-levelled theories - particularly when applied to affect some criminal justice outcome (McGloin and Thomas 2013). A consequence of singlelevelled theories of violence is that preventive strategies that are informed by these theories will affect fewer people than a strategy that addresses violence at individual, interpersonal, community and societal levels. Although traditionally less theoretically rich than criminology, public health has yielded more success in preventing violence because it adopts a multi-levelled social-ecological framework (Brofenbrenner 1979) that views violence as being influenced by interacting individual, interpersonal, community and societal factors and by targeting each level (Dahlberg and Mercy 2009; World Health Organization 2002). Rather than being a collection of theories seeking to explain cognate or related phenomena, the social-ecological approach is a framework for modelling behaviour. It can comprise theories from any number of disciplines - and is strengthened by this - but at its heart is the assertion that individual behaviour does not happen in a vacuum: it is shaped by individual, interpersonal, organisational and societal factors. While this approach is more complex but less refined than single-levelled theories and necessitates more expansive programmes of intervention (e.g. Scottish Violence Reduction Unit 2017), it has a greater likelihood of effecting population-level change. In recognition of the considerable evidence that violence can be affected by mechanisms at each of these levels and seeking to inform a broad violence prevention strategy, this paper adopts a social-ecological perspective to identifying risk factors for 
weapon-carrying. The following overview details the existing explanations of weapon-carrying in the international literature across the levels of the socialecological model.

\section{Individual-level risk factors}

At the centre of the social-ecological model is the individual, consisting of demographic, experiential and attitudinal risk factors.

Demographic risk factors: Males are between two (McVie 2010; Hemenway et al 2011) and five (Molnar et al 2004; Tigri et al 2016) times more likely to report carrying a weapon than females and weapon-carrying tends to peaks in midadolescence (Swahn et al 2013; Haegerich et al 2014; Hemenway et al 2011; Ilie et al 2016). Studies that have directly compared ethnic groups have found that minority groups are at heightened risk of carrying a weapon compared to white respondents (Hemenway et al 2011; Molnar et al 2004; Swahn et al 2013). The risk associated with socioeconomic factors is unclear because household income is rarely well-captured in self-report surveys completed by young people. Bégue, Roché and Duke (2016) used living in public housing as a proxy for deprivation/affluence and found it to be a protective factor against weaponcarrying. However, Molnar et al (2004) found no relationship between family socioeconomic status and weapon-carrying, nor was there a relationship between weapon-carrying and school lunch eligibility (Williams et al 2002), suggesting that the relationship between deprivation and weapon-carrying is not strong. 
Attitudes: Analysis of non-criminogenic psychological factors has found relatively little that predicts weapon-carrying. Weapon-carrying was more likely in sensation seekers (Thurnherr et al 2009) and McVie (2010) found that low selfesteem was weakly associated with weapon-carrying. Criminogenic attitudes have greater explanatory power: Bégue et al (2016) found that pro-delinquent attitudes positively predicted weapon-carrying, although, given the theoretical link, the relationship was surprisingly weak. Importantly, that study found no link between trust in authorities and weapon-carrying, which is relevant to the discussion of trust in the police below.

Victimisation and offending: The two most fundamental explanations for why someone might carry a weapon are because they expect to be either a victim or a perpetrator of violence. Both positions have received considerable empirical scrutiny. To those familiar with the extensive literature on victim-offender overlap, treating 'victims' and 'offenders' as mutually exclusive is naïve. That issue notwithstanding, efforts to reduce weapon-carrying and use would benefit from knowing the relative effects of offensive and defensive motives on this behaviour. Fortunately, several studies have compared the relative weight of victimisation and offending on the decision to carry a weapon, albeit through proxy variables rather than direct questioning about motives. Studies have tended to compare the relative effects of recent violent victimisation and recent violent offending, judging that these variables can reveal something about motives for subsequent or concurrent weapon-carrying. Analyses that have included recent experience of both victimisation and offending have consistently 
shown recent offending to be a stronger predictor of weapon-carrying than victimisation (McVie 2010; Saukkonen et al 2016; Kodjo, Auinger and Ryan 2003; Spano, Pridemore and Bolland 2012). However, two studies are notable for their dissent. Yun and Hwang's (2011) analysis of predictors of carrying a weapon in school found that prior victimisation far outweighed violent delinquency. However, the types of victimisation that were used to generate their violent victimisation variable ("being threatened at gun or knifepoint; being shot at; being stabbed; and being jumped", p.371) are heavily weighted towards weapon violence and more extreme than those typically used in other studies (reflected in a low mean score of 0.36 on a $0-8$ scale). This also resonates with the very strong relationship between weapon-carrying and being threatened or attacked with a knife reported by Webster, Gainer, and Champion (1993; odds ratio 5.74 for males) and Khubanchandani and Price (2017; odds ratio 5.14). Therefore, it is doubtful that Yun and Hwang's study can be regarded as showing that victimisation outweighs offending in the decision to carry a weapon, but is more a reflection of a linear relationship between the severity of violent victimisation and weapon-carrying. Secondly, Spano and Bolland (2013) found that controlling for baseline violent victimisation neutralised the relationship between baseline violent offending and gun-carrying at one-year follow-up. However, their later paper (Spano et al 2012), which accommodated victimoffender overlap, reversed the findings and gave greater weight to violent offending as an explanation of weapon-carrying. 
Fear of victimisation: Beyond actual experience of victimisation, weaponcarrying may be driven by the anticipation of victimisation or by concerns about safety. Carrying a weapon is a plausible response to most conceptualisations of fear of crime (Farrall, Jackson, and Gray 2009). A weapon can give confidence to the carrier, it can be used to deter violence and, theoretically, it reduces the risk of harm to oneself if an encounter becomes violent (Brennan 2017). Therefore, an association between weapon-carrying and fear of victimisation or worry about personal safety is plausible. Despite this logical connection, the supporting evidence for a relationship between fear of crime and weapon-carrying is weak. Although Hemenway et al (2011) found that weapon-carrying was slightly more likely among respondents who "never or rarely felt safe" (p.1000), this relationship was not statistically significant once the model controlled for other variables. Saukkonen et al (2016) found that a 'sense of security' was only predictive of carrying a gun, but not of carrying a knife or other weapon and Spano and Bolland (2013) found that fear of crime at baseline did not predict weapon-carrying one year later.

Deviant identity: Carrying a weapon, and making this known to others may be a way of shaping one's identity. Given the danger that many people associate with weapons, carrying one is an easy way to express deviant tendencies. Therefore, rather being driven by directly violent motives (offensive or defensive), weaponcarrying may simply reflect a general antisocial disposition or a desire to convey this. This has been examined in the literature in several ways. Researchers have directly measured antisocial attitudes or beliefs (Webster et al 1993; Bégue et al 
2016; Williams et al 2002), school exclusion (Kodjo et al 2003), arrest (Williams et al 2002), general offending behaviour (McVie 2010; Saukkonen et al 2016; Thurnherr et al 2009; Barlas and Egan 2006) or they have employed a proxy for deviance, most commonly substance use (McVie 2010; Williams et al 2002;

Khubanchandani and Price 2017; Ilie et al 2017; Buschmann et al 2017;

Thurnherr et al 2009). Substance use is an imperfect proxy for deviance because behaviours associated with drug use may involve the use of a weapon, particularly if the respondent is involved in drug distribution. Nonetheless, it has value as an indicator of a more general deviance or disregard for the law. In general, these studies have identified a relationship between deviant attitudes or behaviour that is independent of violent victimisation and violent offending.

While these studies have not yielded deeper insight than a statistical association between general deviance and weapon-carrying, Harcourt's (2006) analysis of interviews with convicted gun carriers suggested that weapons offer far more than a rational response to threat: they are a means through which (anti)social bonds are formed and a prop for the expression of (deviant) identity.

\section{Interpersonal risk factors}

By definition, violence is an interaction between two or more people. Therefore, interpersonal factors are likely to play an important role in weapon-carrying behaviour. In particular, peer influence, as a major source of information about threat and violence, should play a role. From a rational perspective, an individual may learn about the prevalence of weapon-carrying in their environment through exposure to peer weapon-carrying and respond accordingly. 
Alternatively, taking a differential association approach, someone may carry a weapon to reflect the behaviours of a deviant peer group.

In the US literature, the influence of both of these factors have been considered. Peer deviance was constructed in a number of ways. Firstly, respondents were often asked to describe the extent to which their peers had committed crimes or to estimate the diversity of that offending. Secondly, peer delinquency was inferred if a respondent indicated that they were a member of a gang. The effect sizes for the latter (e.g. Spano and Bolland 2013 and Hemenway et al 2011, reported odds ratios of 4.70 or greater) were typically stronger than for the former (usually up to an odds ratio of 2: McVie 2010; Saukkonen et al 2016). While general peer deviance has received a lot of attention in the literature, relatively few studies have estimated the relationship between perceived peer weapon-carrying and respondent weapon-carrying. Given the contagion effects of weapon-carrying that have been demonstrated at the group- and communitylevels, this is an unfortunate oversight. When this relationship has been tested, it has been shown to be a very strong predictor of weapon-carrying. Williams et al (2002) found that having at least two of a respondent's four best friends carrying a gun in the past year was associated with an eleven-fold increase the likelihood of ever having carried a gun.

Two important studies have uncovered more about the relationship between peer and respondent weapon-carrying than simple statistical association. Firstly, Hemenway et al (2011) found that young people tended to overestimate the 
prevalence of weapon-carrying among their peers. Importantly, they also found that this effect is particularly pronounced among weapon-carriers. This miscalculation, which creates a positive feedback loop that reinforces weaponcarrying, could explain the observed contagion effects within communities.

Secondly, in a longitudinal, social network analysis, Djikstra et al (2010) provided robust evidence that when a peer begins to carry a weapon, it has a transformative effect on the weapon-carrying behaviour of the respondent: "participants were 2.29 times more likely to make a move towards their friends' weapon-carrying average than not to change their weapon-carrying" (p. 205). Taken together, these two findings highlight the importance of peer behaviour on weapon-carrying and also suggest that intervening through peer influence is a potentially fruitful preventive mechanism.

\section{Community risk factors}

If weapon-carrying is driven by perceived need for self-protection, weaponcarrying should be more likely in neighbourhoods with higher rates of weaponcarrying and violence. Similarly, if weapon-carrying is driven by violent intentions, weapon-carrying would be rational in riskier areas as an intended victim has a higher likelihood of carrying a weapon. Rennison, Jacques and Berg (2011) provided indirect support for this by demonstrating that weapon use in violence was more common against neighbourhood outsiders. Presumably this reflected assailant attempts to overcome the uncertainty of a violent encounter with a stranger who might be armed. 
Studies have demonstrated that weapon-carrying and the type of weapon carried are influenced by the characteristics of the weapon carrier's neighbourhood. The most commonly-tested relationship is that between neighbourhood deprivation and weapon-carrying. Baumer et al (2003) showed that firearms were more likely to be used in assaults in deprived neighbourhoods than in more affluent ones. In contrast, Molnar et al (2004) found that neighbourhood poverty did not predict the carrying of concealed firearms in Chicago and Yun and Hwang (2011) found that neighbourhood disadvantage did not predict carrying a weapon to school.

Beyond a rational response to threat or efforts to overcome uncertainty in violent situations, a neighbourhood can have a less direct influence on weapon-carrying: Exposure to violence and weapon-carrying may inoculate a person against the seriousness of violence (Mrug, Madan and Windle 2016); weak informal social control may limit the extent to which a community can inhibit violence (Haegerich et al 2014); and physical signs of disorder may foster injunctive norms that violence is permissible in this area (Keizer, Lindenberg and Steg 2008). The supporting evidence for these theories varies. In a survey of high school students in Boston, Hemenway et al(1993) found that the more victims of violence a respondent knew, the higher their likelihood of carrying a firearm, but this relationship did not predict carrying a knife and concern about neighbourhood gun violence did not predict weapon-carrying. Spano et al (2012) found that exposure to community violence - experienced and witnessed predicted weapon-carrying at one-year follow-up. However, when violent 
behaviour was statistically controlled, no relationship between exposure and weapon-carrying was found to exist. Both findings suggest something more complex than simple neighbourhood exposure driving weapon-carrying. More convincingly, Haegerich et al (2014) found a negative relationship between informal social control and weapon-carrying and Molnar et al (2004) found that collective efficacy - a combination of social cohesion and informal social control was a strong protective factor against weapon-carrying. Finally, Molnar et al (2004) have shown that visible neighbourhood physical and social disorder are positively associated with weapon-carrying, but Haegerich et al (2014) found no relationship between the two.

In summary, the evidence for a link between neighbourhood and violence is moderated by the perceived level of violence rather than more tangible factors such as economic deprivation. Importantly, none of the studies that sought to test for neighbourhood effects on weapon-carrying included a robust estimate of violence or weapon use in that neighbourhood using police or health statistics. This may be a consequence of respondent-identifiable data not being available to researchers. In addition, indicators of the most useful phenomenon - prevalence of weapon-carrying - are not routinely available. This is problematic because an important confounding factor may have been overlooked in the analyses of this social-ecological level raising the risk of Type I and Type II errors. It also highlights a research and practical limitation of violence prevention, that smallarea estimates of weapon-carrying are extremely rare: none exist in Europe and 
even in the US, the illegal nature of much weapon-carrying necessitates the use of proxy estimates such as firearm suicides (Azrael, Cook and Miller 2004).

\section{Societal risk factors}

An analysis of societal risk factors for weapon-carrying requires a reliable metric of weapon-carrying at a population-level. As noted, a sufficiently granular metric does not exist for illegal weapon-carrying by young people in England and Wales (Tiratelli, Quinton and Bradford 2018). Proxy variables, such as murder and police-recorded violence involving a weapon exist in many countries and have been used to determine the impact of legislative changes in the availability of firearms on weapon violence (McPhedran 2016; Cook 2018), but the focus of these studies on legal weapon ownership by adults limits their value for understanding illegal weapon-carrying by young people.

\section{Weapon-carrying and trust in the police}

This section puts forward a theoretical basis for a previously untested potential driver of weapon-carrying: trust in police competence. (Jackson and Bradford 2010). Harcourt describes how the respondents in his interviews have little faith in the ability of the police or the state to protect them from violence. This belief provides a rationale for carrying a weapon. In Harcourt's interviews, many respondents were engaged in drug-dealing or gang membership - occupations that offer little routine protection from police and, when disputes arise, inhibit the use of law via police to resolve the issue. These respondents are probably not typical of weapon-carriers in England and Wales, but being engaged in criminal 
activity is not a requirement for having reduced levels of trust in police competence (Bradford and Myhill 2014).

An alternative interpretation of 'trust in the police' is a trust in the police to execute their roles fairly (Jackson and Bradford 2010). Trust in police fairness can be based on direct or vicarious experience of police discrimination, a reflection of community norms or even societal-level distrust of the police. This type of distrust could also explain weapon-carrying, but more as being endogenous of general anti-police attitudes than having a direct causal link. It is important that Bégue et al(2016) found no link between weapon-carrying and distrust of authorities. However, this is the only test of this relationship in the literature and a distrust of police fairness or competence may be more specific than a general distrust of authorities. Finally, it is unclear if this is a post hoc technique of neutralisation (Sykes and Matza 1957) or if it reflects a reasoned decision in a violent environment: either explanation is credible. A third explanation is that a lack of trust in the police's ability to protect them is an expression of disdain for the police as an organisation rather than a realistic evaluation of threat. Indeed, the three explanations need not be mutually exclusive and any relationship between weapon-carrying and trust in police competence would require further exposition. Given the multiple causal mechanisms through which trust in the police may affect weapon-carrying, this paper tests the relationship between this attitude and weapon-carrying. 


\section{Hypotheses}

Following a summary of the risk factors for carrying a weapon by a young person identified in an international collection of studies, this paper seeks to add to the literature by identifying risk factors for weapon-carrying by young people in England and Wales. As can be seen from the literature detailed above, the list of risk factors is long and important influencers can be found at all levels of the social-ecological model. Informed by this literature and organised around the critical masses of evidence, this paper tests the contribution of five blocks of variables to the explanation of weapon-carrying: demographic factors, victimisation, antisocial behaviours and attitudes, deviant peer influence and neighbourhood characteristics. As the first analysis of this behaviour with a national sample in England and Wales, the study is exploratory, resulting in a large number of hypotheses being tested. Adjustments to the threshold for statistical significance to accommodate the exploratory and multi-test nature of this study are described below.

The hypotheses on which these models are based are:

\section{Demographics}

1. Weapon-carrying is more likely among males

2. The relationship between age and weapon-carrying is non-linear with a peak in the mid-teenage years

3. Weapon-carrying is more likely in ethnic minority respondents 
Antisocial behaviours

4. Weapon-carrying is more likely among those with a history of violent offending

5. Weapon-carrying is more likely among those with a history of drug use

6. Weapon-carrying is negatively related to trust in the police

\section{Victimisation}

7. Weapon-carrying is more likely among those who have been threatened with violence

8. Weapon-carrying is more likely among those who have been victims of violence

\section{Deviant peers}

9. Peers offending history is associated with an increased likelihood of carrying a weapon

\section{Neighbourhood characteristics}

10. Weapon-carrying is less likely in safer neighbourhoods

11. Weapon-carrying is more likely in disordered neighbourhoods 


\section{Methods}

\section{Sample}

Conducted in England and Wales, the Offending, Crime and Justice Survey (OCJS) is a survey of self-reported offending in the 12 months preceding completion of the survey. The survey began in 2003 with an initial sample of 10,079. Approximately one-third of these respondents were surveyed again each year until 2006 (inclusive). Between 2004 and 2006, the survey also added up to 2,000 new respondents. This method generated a combined panel and cross $^{-}$ sectional data set with a total of 25,617 completed surveys across 13,538 unique respondents. The sampling of the survey was weighted towards young people: the mean age of respondents was 23.2 years (Minimum 10 years, Maximum 66 years, Standard deviation 13.3 years) and the median age was 18 years (Interquartile range 14-25 years). The dataset for each of the four waves was downloaded from the UK Data Service archive (Home Office Research, Development and Statistics Directorate 2008a; 2008b; 2008c).

For the purposes of this study, which focused on weapon-carrying by young people, the sample was restricted to respondents aged 25 years or younger $(77 \%$ of the total sample) and, because the variable, 'trust in the police', was only introduced in 2004, the data set was restricted to waves 2,3 and 4 (covering 2004-2006). Only the first completed survey from each respondent was included to avoid any potential panel effects; this resulted in a final eligible sample of 6,789 respondents. The pooling of data sets is common practice in the modelling of relatively rare events (such as weapon-carrying) and the use of multiple waves 
was possible due to the consistent wording of questions over waves. Wave was included as a covariate in each of the models, but was not found to be a statistically significant predictor of weapon-carrying, nor did it substantially affect the relationship between weapon-carrying and any of the other variables in the models. Consequently, it was excluded from the results presented below.

\section{Measures}

Carrying a weapon. Respondents were asked if they had carried a knife or gun with them for their own protection, for use in crimes or in case they got into a fight. This was coded as a binary indicator and served as the outcome variable.

Demographic factors

Respondent sex was coded as a binary variable. Age (at the time of completion) was defined in years as a continuous variable and was centred around the mean age. An 'age-squared' variable was included to facilitate testing non-linearity in the relationship between age and weapon-carrying. As the distribution of ethnicity was heavily weighted towards white respondents, using multiple categories of ethnicity would have yielded unstable statistical models.

Consequently, a binary indicator, with 'white' and 'non-white' categories was generated.

Attitudes and dispositional factors

Recent violent behaviour was captured by asking respondents if they had committed any violent offence in the past year. This was coded as a binary 
variable. Drug use in the past year was also a binary variable. Trust in local police was measured on a four-point Likert scale. The response options were "A lot", "A fair amount", "Not very much" and "Not at all".

Personal victimisation factors

Violent victimisation was coded as a binary variable in response to the question "in the last 12 months has anyone used force against you on purpose, for example, scratched, hit or kicked you, or used a weapon of any sort, or been violent to you in any way?". Threat victimisation was coded as a binary variable in response to the question "in the past 12 months, has anyone threatened you in a way that actually frightened you?".

\section{Interpersonal factors}

Criminal peers was measured as a five-point Likert scale in response to the question: "Thinking about your closest friends. About how many of them, if any, have been in trouble with the police in the last 12 months? (not including driving fines)". Response options were: "None of them"; "A few of them"; "Quite a lot of them"; "Nearly all of them"; and "All of them". The distribution of this variable was highly positively skewed with fewer than $0.1 \%$ of respondents indicating that all of their friends had been in trouble with the police in the past year. To achieve a reasonable balance between item validity and model integrity, the variable was reduced to a four-point variable by merging "Nearly all of them" and "All of them" into a single category ("All or nearly all of them"). 
Community factors

Perceived area disorder was created by summing binary responses to the perceived presence of six disorder-related issues in their area: noisy neighbours; teenagers hanging around causing problems; people sleeping rough on the streets or in other public places; people being harassed in the street because of their skin colour; people using or selling drugs; and people being drunk or rowdy in public. Brunton-Smith (2011) has shown, using the OCJS data set, that these items combined can be regarded as a single latent factor, so the scores for these variables were summed to create a single continuous factor. Perceived neighbourhood safety was a four-point ordinal scale. Respondents were asked "how safe would you feel walking or playing alone in this area after dark?". The response options were "very safe", "fairly safe", "fairly unsafe" or "very unsafe".

\section{Analytic strategy}

Logistic regression was used to identify predictors of weapon-carrying. To examine the cross-validity of the results, the data were split in two with years 2004 and 2005 forming the 'training' (n=5,994) and 2006 forming the 'testing' data set $(n=795)$. This temporally-based splitting of the data was chosen to increase confidence in the future predictive value of the models. Variables were introduced in blocks and then included in a 'full' model that included all variables. A final 'best' model was developed using the guidelines for regression model development proposed by Gelman and Hill (2007). 
As the analyses were exploratory and contained a large number of variables, a high threshold for statistical significance was set to reduce the risk of Type II (false positive) errors. The alpha-level was calculated using the Bonferroniadjustment, which is $0.05 / k$, where $k$ is the total number of variables in the model. The ability of the models developed on the 'training' data set to predict weapon-carrying in the 'testing' data set was examined and these statistics are reported in Table 2 as area under the curve (AUC) statistics. The results section also reports confusion matrix statistics for the 'best' model to illustrate its ability of the model to identify weapon-carriers in the test data set.

Reproducibility: All analyses were undertaken using $\mathrm{R}$ statistical software version 3.4.3 (R Core Team 2016) through RStudio version 1.1.423 (RStudio, Inc.). R packages, 'pscl' (Jackman 2017) and 'ROCR' (Sing et al 2005) were employed. The $\mathrm{R}$ syntax used to prepare and analyse the data are available here: https://github.com/iainbrennan/paper-syntax/blob/master/Weaponcarrying\%20and\%20the\%20reduction\%20of\%20violent\%20harm.R and the data sets used (SN5374; SN5601 and SN6000) can be accessed without charge through the UK Data Service: http://www.ukdataservice.ac.uk.

\section{Results}

Four per cent of the respondents reported carrying a weapon at least once in the 12 months preceding their completion of the survey. Table 1 is based on the pooled 2004, 2005 and 2006 data sets and presents descriptive statistics. Table 2 describes the logistic regression models and model fit statistics used in 
predicting weapon-carrying based on the pooled 2004 and 2005 'training' data set.

TABLE ONE ABOUT HERE

TABLE TWO ABOUT HERE

Logistic regression models

In Model 1, examining the contribution of demographic factors, males were approximately three times more likely to carry a weapon than females (H1). Age and age-squared were statistically significant predictors of weapon-carrying, which indicated that a non-linear model was a good fit for the data (H2). In this model, likelihood of weapon-carrying peaked at 17.2 years. There was no statistically significant relationship between ethnicity and weapon-carrying (H3). The model accounted for around $6 \%$ of the variance in weapon-carrying. Area under the curve (AUC) statistics indicate that ability of a model using demographics alone to accurately classify respondents was modest (AUC=0.73).

Model 2 examined the role played by antisocial attitudes and dispositional factors. Respondents who had committed a violent offence in the past year were almost four times as likely to report carrying a weapon than those who were not violent (H4). Drug use (H5) in the past year was also a strong predictor of 
weapon-carrying. The relationship between weapon-carrying and distrust of the police was curvilinear (H6). Respondents who had a fair amount of trust in police in their area were no more likely to carry a weapon than those who had a lot of trust in the police. Respondents who reported having not very much trust in police in their area were two and a half times and those with not trust at all were almost five times more likely to report carrying a weapon than those who had a lot of trust in the police. The model explained a reasonably proportion of the variance in weapon-carrying $-22 \%$ - but the ability of the model to correctly classify respondents was modest $(\mathrm{AUC}=0.76)$.

Model 3 examined the role of victimisation in predicting weapon-carrying. Having been threatened with violence (H7) and having been a victim of violence (H8) were statistically significant predictors of weapon-carrying. However, the model had a weak predictive ability $(\mathrm{AUC}=0.68)$ and explained only five per cent of the variance.

Model 4 examined the role of interpersonal factors on weapon-carrying and contained a single variable - delinquent peers (H9). As the proportion of a respondent's peer had been in trouble with the police in the preceding year increased, weapon-carrying likelihood increased rapidly. Respondents who had 'a few' friends who had been in trouble with the police were almost three and a half times as likely to have carried a weapon compared to those whose friends had not been in trouble with the police. Odds ratios for those who reported that 'quite a lot' and 'all or nearly all' of their friends had been in trouble were 11 and 8.7 
times more likely to have carried a weapon, respectively. The wide confidence intervals suggest that the non-linearity observed in this relationship is more likely a reflection of the skewed distribution of peer delinquency than the actual relationship between the two variables. The model explained $14 \%$ of the variance in weapon-carrying and had modest predictive ability ( $\mathrm{AUC}=0.71)$.

Model 5 explored the contribution of neighbourhood-level factors to weaponcarrying. In this model, the perceived extent of physical and social disorder in a respondent's neighbourhood predicted weapon-carrying (H10), as did respondent fear of walking alone in that neighbourhood after dark (H11). The proportion of variance explained by the model was modest and it was a modest classifier of weapon-carrying $(\mathrm{AUC}=0.68)$.

Model 6 - the 'full' model - contained all 14 variables. Male gender, violence and drug use, little or no trust in the police, deviant peers and area disorder were strong predictors of weapon-carrying. The model explained $33 \%$ of the variance and was a good classifier of weapon-carrying (AUC=0.87).

Model 7 describes the 'best' model. It contains nine variables. In this model, male gender, violent offending in past year, drug use in the past year, lack of trust in the police, violent victimisation and having delinquent peers were all statistically significant predictors of weapon-carrying. The model explained $32 \%$ of the variance and was a good classifier of weapon-carrying ( $\mathrm{AUC}=0.87$ ), 
identifying $56 \%$ of the weapon-carriers in the testing data set (true positive $=21$; true negative $=719$; false positive $=39 ;$ false negative $=16$ ). 


\section{Discussion}

In summary, the risk factors for weapon-carrying among youth people in England and Wales were largely consistent with those for weapon-carrying in the international literature. Importantly, the combined characteristics of male gender, violent behaviour, drug use, little or no trust in the police, deviant peers and neighbourhood disorder identified over half of the weapon-carriers in the test data set. Although the number of weapon-carriers was relatively small, this finding indicates considerable homogeneity among weapon-carriers and holds promise for the targeting of interventions to reduce weapon-carrying among young people. In terms of explaining why young people carry weapons, this paper has demonstrated the value of a multi-levelled, social-ecological explanation of the behaviour and has shown the contribution that criminological variables, such as trust in the police, can make to existing knowledge about the predictors of this behaviour.

Males were around two and a half times more likely to carry a weapon than females; weapon-carrying was non-linearly related to age, with a peak around 17 years - slightly later than in other studies. In the demographic-only model, the relationship between ethnicity and weapon-carrying was not statistically significant. Because the paper set a high threshold for statistical significance and the sample had a relatively low representation of respondents from an ethnic minority, it is likely that the relationship between ethnicity and weaponcarrying is moderated by a number of external factors that needs to be explored in greater detail. Experiencing threats or violent victimisation were strong 
predictors of weapon-carrying. However, this model explained only a small proportion of the variance when other covariates were included in the 'full' and 'best' models, none of the victimisation variables remained statistically significant. This suggests that the statistical relationship is more indicative of a victim-offender overlap than of self-defence being a direct, standalone cause of weapon-carrying. Consistent with this assertion is the observation that weaponcarrying is more strongly associated with antisocial behaviour and anti-police attitudes: violent offending and drug use in the past year and lack of trust in the police were all strong predictors of weapon-carrying. In terms of peer influence, the proportion of friends who had been in trouble with the police was a statistically significant predictor of weapon-carrying, but the relationship was non-linear, with respondents who had 'quite a lot' having greater likelihood of carrying a weapon than those who reported that 'all or nearly all' of their friends had been in trouble with the police. As hypothesised, area characteristics influenced weapon-carrying. The extent of area social disorder and the extent to which a respondent regarded their area as unsafe were statistically significant predictors of weapon-carrying although the amount of variance explained by the 'Area' model was small. Area social disorder remained a statistically significant predictor in the 'full' and 'best' models, but perceived area safety did not. Finally, there was no relationship between the year of data collection and the likelihood of weapon-carrying. This suggests that national-level factors, such as macroeconomic or legislative change had little effect on the risk factors for weapon-carrying over this very short period. 
Factors relating to personal victimisation and perceived area safety predicted weapon-carrying in the more basic models but the contribution was modest when compared to the explanatory power of the variables relating to criminogenic individual-level factors such as recent offending, drug use and trust in the police and the interpersonal factor, deviant peers. Although the pseudo R-squared statistics should not be compared directly, it is difficult to dismiss the vastly superior explanatory power of the latter variables. In terms of theories of weapon-carrying, this suggests that weapon-carrying is more a reflection of a deviant or criminal lifestyle than it is a response to threat or victimisation. However, as noted in the introduction, victim-offender dichotomies are far too simplistic: self-protection should be an important consideration for someone who plans to do violence and, someone who fears violence is probably not immune to the desire to balance the odds of success in their own favour. One potentially fruitful way to think about weapon-carrying is as a technique for reducing the uncertainty of violent encounters (Brennan 2017). For those motivated to commit violence, weapons offer a way to overcome potential resistance, a wider pool of victims, reduced exposure to police detection and both a script (Wilkinson and Fagan 1996) and a point of focus during the 'forward panic' of violence (Collins 2009).

The analysis demonstrates that weapon-carrying behaviour cannot be explained by individual, interpersonal, community or societal factors alone. Indeed, even including variables from this broad range of factors, the 'best' model could only explain around one-quarter of the variance in individual weapon-carrying and 
failed to identify almost half of the weapon-carriers in the test data set. Nonetheless, a social-ecological approach to identifying risk factors and building predictive models offers considerable potential for understanding and responding to weapon-carrying. This has strong relevance for criminological research. As noted earlier, despite efforts to integrate theories of violence, criminology research has a tendency to be theoretically-sophisticated, but focused on a single explanatory mechanism (Sampson and Lauritsen 1994). Plainly, it goes deep but not broad. By comparison, social-ecological approaches accommodate many layers of influence, but are often crude in their measurement and simplistic in their explanation of the proposed mechanism - i.e., broad but not deep. By combining perspectives to reduce the harm of crime, criminology can bring a dimension of theoretical sophistication to harm reduction research that is currently lacking, while assuming the explanatory and preventive advantages of a multi-levelled approach: both broad and deep.

The inclusion of criminological variables - particularly, trust in the police - is a step forward in the explanation of weapon-carrying behaviour. Although public health-informed models of weapon-carrying have included questions about victimisation, offending, peer influence and area safety, none to date have included all of these variables and none have included a question about trust in the police. The role of trust in the police in weapon-carrying is a valuable finding as it reveals a new mechanism through which weapon-carrying may occur. Although young people in high-crime neighbourhoods may be 'over-policed' in terms of 'stop and search' or the prosecution of drug-related offences, they may 
be 'under-policed' in terms of the protection from harm or the deterrent effect that the police offer, leading to weapon-carrying as a form of self-protection. Unfortunately, the simple language of the questionnaire item does not allow the complex dimensions of trust in the police to be unpicked. In this case, low trust in the police could reflect a perceived inability to keep all citizens safe or it could reflect perceived bad intentions towards some citizens. Undeniably, the two types of trust are correlated (Jackson and Bradford 2010), but interventions to reduce weapon-carrying based around police effectiveness or police legitimacy would probably look very different.

The role of trust in the police in the decision to carry a weapon represents an opportunity for the typical responses of public health and criminal justice to converge. As Abt (2017) has noted, public health responses to violence tend to understate the relevance of police to directly and indirectly influence prevention. If trust in the police is a driver of weapon-carrying behaviour and violent harm, then this factor needs to be included in violence prevention strategies that originate in public health and to be embedded in interventions that span the lifecourse, rather than after weapon-carrying has initiated or the drivers of weaponcarrying have taken hold.

\section{Limitations}

Much has changed in the lives of young people since 2004-2006 and the risk factors for weapon-carrying may be somewhat different today. In the intervening years, social media has emerged as a major form of communication and platform 
for identity construction. An insult or threat to reputation can be shared far more widely and rapidly than in the past, potentially increasing the perceived need to protect one's ego and identity in the real world (Irwin-Rogers and Pinkney 2017; Patton, Eschmann and Butler 2013). Social media's popularitydriven algorithms may distort perceptions about the threat and likelihood of serious violence through availability heuristics (Kahneman and Tversky 1973) and the effect of selective exposure to information (Wood 2017), which may affect weapon-carrying decisions.

The analysis is based on cross-sectional data. Consequently, causality and the direction of the relationship between predictors and weapon-carrying cannot be inferred. In order to first identify the variables that best identify weaponcarrying behaviour, cross-sectional analyses were required. As the OCJS contains a longitudinal subsample, in future outputs it will be possible to test the relationship between predictor variables on later weapon-carrying in order to establish a temporal direction.

\section{Conclusion}

The paper identified risk factors for carrying a weapon by young people in England and Wales. Building on the existing international literature, it has demonstrated that risk factors for weapon-carrying exist across the levels of the social-ecological model and that weapon carriers can be distinguished from other respondents using relatively few characteristics. The study has shown that victimisation and concerns about personal safety are relevant to understanding 
weapon-carrying, but they are outweighed by criminogenic factors such as offending behaviour, neighbourhood disorder and lack of trust in the police. The last factor represents an important new direction for future exploration and a potential avenue for intervention to reduce the harm from violence. 
References

Abt, T. (2017), ‘Towards a Framework for Preventing Community Violence among Youth', Psychology, Health and Medicine, 22: 266-85.

Azrael, D., Cook, P. J., and Miller, M. (2004), 'State and Local Prevalence of Firearms Ownership: Measurement, Structure and Trends', Journal of Quantitative Criminology, 20: 43-62.

Barlas, J., and Egan, V. (2006), 'Weapon-Carrying among British Teenagers: The Role of Personality, Delinquency, Sensational Interests, and Mating Effort. Journal of Forensic Psychiatry and Psychology, 17: 53-72.

Baumer, E., Horney, E., Felson, R., and Lauritsen, J. L. (2003), 'Neighborhood Disadvantage and the Nature of Violence', Criminology, 41: 39-71.

Bégue, L., Roché, S., and Duke, A. A. (2016), 'Young and Armed: A CrossSectional Study on Weapon-Carrying among Adolescents', Psychology, Crime and Law, 22: 455-72.

Blumstein, A., and Cork, D. (1996), 'Linking Gun Availability to Youth Gun Violence', Law and Contemporary Problems, 59: 5-24.

Bradford, B., and Myhill, A. (2014), 'Triggers of Change to Public Confidence in the Police and Criminal Justice System: Findings from the Crime Survey for England and Wales Panel Experiment', Criminology and Criminal Justice, 15: $23-43$.

Brennan, I.R. (2017), 'High Stakes: The Role of Weapons in Offender Decision Making' in W. Bernasco, H. Elffers, and J-L. van Gelder, eds., The Oxford Handbook of Offender Decision Making, 421-44. Oxford University Press. 
Brennan, I. R., Moore, S. C., and Shepherd, J. P. (2006), 'Non-Firearm Weapon Use and Injury Severity: Priorities for Prevention', Injury Prevention: 12: $395-9$.

Buschmann, R. N., Prochaska, J. D., Baillargeon, J. G., and Temple, J. R. (2017), 'Firearm Carrying and Concurrent Substance Use Behaviours in a Community-Based Sample of Emerging Adults', Injury Prevention, 23: 3837.

Button, D.M., and Worthen, M. G. F. (2017), 'Applying a General Strain Theory Framework to Understand School Weapon-Carrying among LGBQ and Heterosexual Youth', Criminology, 55: 806-32.

Bronfenbrenner, U. (1979), The Ecology of Human Development: Experiments by Nature and Design. Harvard University Press.

Brunton-Smith, I. (2011), 'Untangling the Relationship Between Fear of Crime and Perceptions of Disorder: Evidence from a Longitudinal Study of Young People in England and Wales', British Journal of Criminology, 51: 885-99. Collins, R. (2008), Violence: A Micro-Sociological Analysis. Princeton University Press.

Cook, P. J. (1979), 'The Effect of Gun Availability on Robbery and Robbery Murder: A Cross-section Study of Fifty States' in R. H. Haveman, and B. B. Zeller, eds., Policy Studies Review Annual, vol. 3, 743-81. Sage.

Cook, P.J. (2018), 'Gun Markets’, Annual Review of Criminology, 1: 359-77.

Dahlberg, L. L., and Mercy, J. A. (2009), 'History of Violence as a Public Health Issue'. AMA Virtual Mentor, 11: 167-72. 
Dijkstra, J. K., Lindenberg, S., Veenstra, R., Steglich, C., Isaacs, J., Card, N. A., and Hodges, E. V. E. (2010), 'Influence and Selection Processes in Weapon' Carrying During Adolescence: The Roles of Status, Aggression and Vulnerability', Criminology, 48: 187-220.

Farrall, S., Jackson, J., and Gray, E. (2009), Social Order and the Fear of Crime in Contemporary Times. Oxford University Press.

Gelman, A., and Hill, J. (2007), Data Analysis using Regression and Multilevel/Hierarchical Models. Cambridge University Press.

Haegerich T. M, Oman, R. F, Vesely, S. K, Aspy, C. B, and Tolma, E. L. (2014), 'The Predictive Influence of Family and Neighborhood Assets on Fighting and Weapon-Carrying from Mid- to Late-Adolescence', Prevention Science, 15: 473-84.

Harcourt, B. (2006), Language of the Gun: Youth, Crime, and Public Policy. University of Chicago Press.

Hemenway, D., Vriniotis, M., Johnson, R. M., Miller, M., and Azrael. D. (2011), 'Gun Carrying by High School Students in Boston, MA: Does Overestimation of Peer Gun Carrying Matter?' Journal of Adolescence, 34: 997-1003.

HM Government (2018), Serious Violence Strategy. HM Government.

Home Office. Research, Development and Statistics Directorate. Offending Surveys and Research, National Centre for Social Research, BMRB. Social Research. (2008a). Offending, Crime and Justice Survey, 2004. [data collection]. 4th Edition. UK Data Service.

$\mathrm{SN}: 5374$, http://doi.org/10.5255/UKDA-SN-5374-1 
Home Office. Research, Development and Statistics Directorate. Offending Surveys and Research, National Centre for Social Research, BMRB. Social Research. (2008b). Offending, Crime and Justice Survey, 2005. [data collection]. 3rd Edition. UK Data Service. SN: 5601, http://doi.org/10.5255/UKDA-SN-5601-1

Home Office. Research, Development and Statistics Directorate. Offending Surveys and Research, National Centre for Social Research, BMRB. Social Research. (2008c). Offending, Crime and Justice Survey, 2006. [data collection]. 2nd Edition. UK Data Service. SN: 6000, http://doi.org/10.5255/UKDA-SN-6000-1

Ilie, G., Mann, R. E., Boak, A., Hamilton, H. A., Rehm, J., and Cuismano, M. D. (2017), 'Possession of Weapon and School Violence among Adolescents and their Association with History of Traumatic Brain Injury, Substance Use and Mental Health Issues', Injury, 48: 285-92.

Irwin-Rogers, K., and Pinkney, C. (2017), Social Media as a Catalyst and Trigger for Youth Violence. Catch-22.

Jackman, S. (2017), pscl: Classes and Methods for R Developed in the Political Science Computational Laboratory, United States Studies Centre, University of Sydney. Sydney, New South Wales, Australia. R package version 1.5.2. URL https://github.com/atahk/pscl/

Jackson, J., and Bradford, B. (2010), 'What is Trust and Confidence in the Police?', Policing, 4: 241-8.

Jones, S. (2017), 'Knife crime is an epidemic. Do we care enough to look for a cure?' Guardian, 30 th November 2017. 
https://www.theguardian.com/commentisfree/2017/nov/30/knife-crime-

epidemic-cross-government-programme-violence

Kahnemann, D., and Tversky, A. (1973), 'Availability: A Heuristic for Judging

Frequency and Probability', Cognitive Psychology, 5: 207-32.

Kalesan, B., Mobily, M., Keiser, O., Fagan, J. A., and Galea, S. (2016), 'Firearm

Legislation and Firearm Mortality in the USA: A Cross-Sectional, State-

Level Study', Lancet, 387: 1847-55.

Keizer, K., Lindenberg, S., and Steg, L. (2008), 'The Spreading of Disorder', Science, 322(5908), 1681-5.

Khubchandani, J., and Price, J. H. (2018), 'Violence Related Behaviors and

Weapon-Carrying Among Hispanic Adolescents: Results from the National

Youth Risk Behavior Survey, 2001-2015', Journal of Community Health, 43: $391-9$.

Kodjo, C. M., Auinger, P., and Ryan, S. A. (2003), 'Demographic, Intrinsic, and Extrinsic Factors Associated with Weapon-Carrying at School', Archives of Pediatrics and Adolescent Medicine, 157: 96-103.

Lemos, G. (2004), Fear and Fashion: The Use of Knives and Other Weapons by Young People. Lemos \& Crane.

Mayor of London (2017), The London Knife Crime Strategy. Greater London Authority.

McGloin, J. M., and Thomas, K. J. (2013), 'Experimental tests of criminological theory', in B. C. Welsh, A. A. Braga, and G. J. Bruinsma, eds., Experimental Criminology: Prospects for Advancing Science and Public Policy, 15-42.

Cambridge University Press. 
McLeroy, K. R., Bibeau, D., Steckler, A., and Glanz, K. (1988), 'An Ecological

Perspective on Health Promotion Programs', Health Education and Behavior, 15: $351-377$.

McPhedran, S. (2016), 'A Systematic Review of Quantitative Evidence about the Impacts of Australian Legislative Reform on Firearm Homicide', Aggression and Violent Behavior, 28: 64-72.

McVie, S. (2010), 'Gang Membership and Knife Carrying: Findings from the Edinburgh Study on Youth Transitions and Crime'. Scottish Centre for Crime and Justice Research.

Metropolitan Police Service (2018), Stop Knife Crime. Available at: https://www.met.police.uk/StopKnifeCrime [Accessed 16 March 2018].

Molnar, B. E., Miller, M. J., Azrael, D., and Buka, S. L. (2004), 'Neighborhood Predictors of Concealed Firearm Carrying among Children and Adolescents', Archives of Pediatric and Adolescent Medicine, 158: 657-64.

Mrug, S., Madan, A., and Windle, M. (2016), 'Emotional Desensitization to Violence Contributes to Adolescents' Violent Behavior', Journal of Abnormal Child Psychology, 44: 75-86.

Office for National Statistics (2017), Crime in England and Wales: Year Ending June 2017. Office for National Statistics.

Patton, D. U., Eschmann, R. D., and Butler, D. A. (2013), 'Internet Banging: New Trends in Social Media, Gang Violence, Masculinity and Hip Hop', Computers in Human Behavior, 29: A54-9. 
Rennison, C. M., Jacques, S., and Berg, M. T. (2010), 'Weapon Lethality and Social Distance: A National Test of Social Structural Theory', Justice Quarterly, 28: 576-605.

Sampson, R. J., and Lauritsen, J. L. (1994), 'Violent Victimization and Offending: Individual-, Situational-, and Community-Level Risk Factors', in A. J. Reiss, Jr., and J. A. Roth, eds., Understanding and Preventing Violence, vol. 3, 1114. National Academy Press.

Saukkonen, S., Laasjalo, T., Jokela, M., Kivivuori, J., Salmi, V., and Aronen, E. T. (2016), 'Weapon-Carrying and Psychopathic-like Features in a Population-based Sample of Finnish Adolescents', European Child and Adolescent Psychiatry, 25: 183-91.

Scottish Violence Reduction Unit (2017), Scottish Violence Reduction Unit: Ten Year Strategic Plan. Violence Reduction Unit.

Sherman, L., Neyroud, P., and Neyroud, E. (2016), 'The Cambridge Crime Harm Index: Measuring Total Harm from Crime Based on Sentencing Guidelines', Policing, 10: 171-83.

Sing, T., Sander, O., Beerenwinkel, N., and Lengauer, T. (2005). 'ROCR: visualizing classifier performance in R', Bioinformatics, 21: 7881. http://rocr.bioinf.mpi-sb.mpg.de.

Spano, R., and Bolland, J. (2013), 'Disentangling the Effects of Violent Victimization, Violent Behavior, and Gun Carrying for Minority Inner-City Youth Living in Extreme Poverty', Crime and Delinquency, 59: 191-213. Spano, R., Pridemore, W.A., and Bolland, J. (2012), 'Specifying the Role of Exposure to Violence and Violent Behavior on Initiation of Gun Carrying: A 
Longitudinal Test of Three Models of Youth Gun Carrying', Journal of Interpersonal Violence, 27: 158-76.

Statistics Canada (2009), Measuring Crime in Canada: Introducing the Crime Severity Index and Improvements to the Uniform Crime Reporting Survey. Minister of Industry.

Swahn, M. H., Bossarte, R. M., Palmier, J. B., Yao, H., and Van Dulem, M. H. M. (2013), 'Psychosocial Characteristics Associated with Frequent Physical Fighting: Findings from the 2009 National Youth Risk Behavior Survey', Injury Prevention, 19: 143-6.

Sykes, G. M., and Matza, D. (1957), 'Techniques of Neutralization: A Theory of Delinquency', American Sociological Review, 22: 664-70.

Thurnherr, J., Michaud, P-A., Berchtold, A., Akré, C., and Suris, J-C. (2009), 'Youths Carrying a Weapon or Using a Weapon in a Fight: What Makes the Difference?, Health Education Research, 24: 270-9.

Tigri, H. B., Reid, S., Turner, M. G., and Devinney, J. M. (2016), 'Investigating the Relationship Between Gang Membership and Carrying a Firearm: Results from a National Sample', American Journal of Criminal Justice, 41: $168-84$.

Tiratelli, M., Quinton, P., and Bradford, B. (2018), 'Does Stop and Search Deter Crime? Evidence from Ten Years of London-Wide Data', British Journal of Criminology. https://doi.org/10.1093/bjc/azx085

Tracy, M., Braga, A. A., and Papachristos, A. V. (2016), 'The Transmission of Gun and Other Weapon-Involved Violence within Social Networks', Epidemiologic Reviews, 38: 70-86. 
United Nations Office on Drugs and Crime (2013). Global Study on Homicide. UNODC.

Van Dijk, A., and Crofts, N. (2017), 'Law Enforcement and Public Health as an Emerging Field', Policing and Society, 27: 261-75.

Webster, D. W., Gainer, P. S., and Champion, H. R. (1993), 'Weapon-Carrying among Inner-City Junior High School Students: Defensive Behavior vs Aggressive Delinquency', American Journal of Public Health, 83: 1604-8.

Wilkinson, D., and Fagan, J. (1996). 'The Role of Firearms in Violence "Scripts":

The Dynamics of Gun Events among Adolescent Males', Law and Contemporary Problems, 59: 55-89.

Williams, D. J., and Donnelly, P. D. (2014), 'Is Violence a Disease? Situating Violence Prevention in Public Health Policy and Practice', Public Health, 128: $960-7$.

Williams, S., Mulhall, P. F., Reis, J. S., and De Ville, J. O. (2002), 'Adolescents Carrying Handguns and Taking them to School: Psychosocial Correlates among Public School Students in Illinois', Journal of Adolescence, 25: 55167.

Wood, M. A. (2018). Antisocial Media: Crime-Watching in the Internet age. Palgrave Macmillan.

World Health Organization (2002), World report on violence and health. World Health Organization.

World Health Organization (2010), European report on preventing violence and knife crime among young people. World Health Organization. 
Yun, I., and Hwang, E. (2011), 'A Study of Occasional and Intensive Weapon` carrying Among Adolescents Using a Nationally Representative Sample'. Youth Violence and Juvenile Justice, 9: 366-82.

Zimring, F. E. (1968). 'Is Gun Control Likely to Reduce Violent Killings?'

University of Chicago Law Review, 35: 721-37. 
Table 1. Descriptive statistics

$\mathbf{n}$

$\%$

\begin{tabular}{|c|c|c|}
\hline \multicolumn{3}{|l|}{ Weapon-carrying } \\
\hline Yes & 245 & 4.1 \\
\hline No & 5,749 & 95.9 \\
\hline \multicolumn{3}{|l|}{ Sex } \\
\hline Male & 2,983 & 49.8 \\
\hline Female & 3,011 & 50.2 \\
\hline Age (years) & 5,994 & $\mathrm{M}=16.68, \mathrm{SD}=4.22$ \\
\hline \multicolumn{3}{|l|}{ Ethnicity } \\
\hline White & 5,412 & 90.3 \\
\hline Non-white & 581 & 9.7 \\
\hline Area disorder & 5,994 & $\mathrm{M}=1.43, \mathrm{SD}=1.34$ \\
\hline \multicolumn{3}{|l|}{ Area safety } \\
\hline Very safe & 1,111 & 18.6 \\
\hline Fairly safe & 3,067 & 51.3 \\
\hline Fairly unsafe & 1,241 & 20.7 \\
\hline Very unsafe & 561 & 0.09 \\
\hline \multicolumn{3}{|l|}{ Violence } \\
\hline Yes & 999 & 17.19 \\
\hline No & 4,813 & 82.81 \\
\hline \multicolumn{3}{|l|}{ Drug use } \\
\hline Yes & 1,163 & 19.85 \\
\hline No & 4,697 & 81.15 \\
\hline \multicolumn{3}{|l|}{ Trust in the police } \\
\hline A lot & 1,304 & 22.42 \\
\hline A fair amount & 3,161 & 54.35 \\
\hline Not very much or not at all & 1,351 & 23.22 \\
\hline \multicolumn{3}{|l|}{ Victim of violence } \\
\hline Yes & 1,191 & 19.88 \\
\hline No & 4,799 & 80.12 \\
\hline \multicolumn{3}{|l|}{ Threatened with violence } \\
\hline Yes & 739 & 12.33 \\
\hline No & 5,253 & 87.77 \\
\hline \multicolumn{3}{|c|}{ Proportion of friends in trouble with police } \\
\hline None & 4,284 & 76.60 \\
\hline A few & 1,309 & 21.6 \\
\hline More than a few & 100 & 1.79 \\
\hline
\end{tabular}


Table two. Logistic regression models

\begin{tabular}{|c|c|c|c|c|c|c|c|c|c|c|c|c|c|c|}
\hline Variable (reference category) & Demo & raphics & Ant & social & Victio & isation & Devi & nt peers & Neigh & ourhood & Full & model & Best & model \\
\hline & OR & $95 \% \mathrm{CI}$ & OR & $95 \% \mathrm{CI}$ & OR & $95 \% \mathrm{CI}$ & OR & $95 \% \mathrm{CI}$ & OR & $95 \% \mathrm{CI}$ & OR & $95 \% \mathrm{CI}$ & OR & $95 \% \mathrm{CI}$ \\
\hline Sex (Female): Male & $3.41^{* * *}$ & $2.53-4.61$ & & & & & & & & & $2.77^{* * * *}$ & $1.94-3.94$ & $2.81^{* * *}$ & $1.99-3.95$ \\
\hline Age & $2.83^{* * *}$ & $2.03-3.94$ & & & & & & & & & 1.41 & $0.96-2.08$ & 1.42 & $0.97-2.09$ \\
\hline Age squared & $0.97^{* * *}$ & $0.96-0.98$ & & & & & & & & & $0.99^{*}$ & $0.98-1.00$ & $0.99^{*}$ & $0.98-0.99$ \\
\hline Ethnicity (White): Non-white & 1.43 & $0.97-2.11$ & & & & & & & & & 1.54 & $0.96-2.46$ & 1.54 & $0.97-2.46$ \\
\hline Violence in past year (No): YeS & & & $4.37^{* * * *}$ & $3.28-5.83$ & & & & & & & $2.79^{* * *}$ & $2.02-3.87$ & $2.85^{* * *}$ & $2.06-3.93$ \\
\hline Drug use in past year (No): Yes & & & $2.67^{* * *}$ & $1.99-3.57$ & & & & & & & $2.36^{* * *}$ & $1.67-3.32$ & $2.41^{* * *}$ & $1.71-3.38$ \\
\hline Trust in police (A lot): $A$ fair amount & & & 1.30 & $0.82-2.07$ & & & & & & & 1.32 & $0.80-2.18$ & 1.26 & $0.76-2.07$ \\
\hline Not very much or not at all & & & $2.91^{* * *}$ & $1.83-4.62$ & & & & & & & $2.25^{* *}$ & $1.35-3.78$ & $2.27^{* *}$ & $1.36-3.79$ \\
\hline Victim of violence (No) Yes & & & & & $3.22^{* * *}$ & $2.46-4.22$ & & & & & 1.33 & $0.92-2.02$ & $1.54^{* *}$ & $1.11-2.12$ \\
\hline Threatened with violence (No) Yes & & & & & $1.67^{* * *}$ & $1.21-2.29$ & & & & & 1.17 & $0.86-1.93$ & & \\
\hline Peers in trouble with police (None): $A$ few & & & & & & & $3.51^{* * *}$ & $2.64-4.66$ & & & 1.56 & $1.15-2.20$ & $1.62^{* *}$ & $1.17-2.23$ \\
\hline More than a few & & & & & & & $8.15^{* * *}$ & $4.67-14.22$ & & & 2.24 & $1.17-4.29$ & $2.28^{*}$ & $1.20-4.35$ \\
\hline Disorder & & & & & & & & & $1.49^{* * *}$ & $1.36-1.63$ & $1.26^{* *}$ & $1.13-1.41$ & $1.25^{* * *}$ & $1.12-1.39$ \\
\hline Area safety (Very safe): Fairly safe & & & & & & & & & $0.40^{* * * *}$ & $0.30-0.55$ & 0.62 & $0.43-0.90$ & & \\
\hline Fairly unsafe & & & & & & & & & $0.33^{* * * *}$ & $0.22-0.49$ & 0.63 & $0.39-1.02$ & & \\
\hline Very unsafe & & & & & & & & & $0.38^{* * * *}$ & $0.24-0.62$ & 0.91 & $0.49-1.66$ & & \\
\hline$N$ & 5,993 & & 5,526 & & 5,988 & & 5,593 & & 5,980 & & 5,218 & & 5,228 & \\
\hline McFadden's $\mathrm{R}^{2}$ & 0.06 & & 0.22 & & 0.05 & & 0.14 & & 0.05 & & 0.33 & & 0.32 & \\
\hline AUC & 0.73 & & 0.80 & & 0.66 & & 0.71 & & 0.68 & & 0.88 & & 0.87 & \\
\hline
\end{tabular}

